\title{
Dehydrozingerone Inspired Styryl Hydrazine Thiazole Hybrids as Promising Class of Antimycobacterial Agents
}

\author{
Girish A. Hampannavar, ${ }^{\dagger}$ Rajshekhar Karpoormath, ${ }^{*}{ }^{\dagger}$ Mahesh B. Palkar, ${ }^{\S}{ }^{\dagger}$ Mahamadhanif S. Shaikh, ${ }^{\dagger}$ \\ and Balakumar Chandrasekaran ${ }^{\dagger}$ \\ ${ }^{\dagger}$ Department of Pharmaceutical Chemistry, Discipline of Pharmaceutical Sciences, College of Health Sciences, University of \\ KwaZulu-Natal, Westville Campus, Durban 4000, South Africa \\ ${ }^{\S}$ Department of Pharmaceutical Chemistry, K.L.E. University College of Pharmacy, Vidyanagar, Hubballi 580031, Karnataka, India
}

Supporting Information

ABSTRACT: Series of styryl hydrazine thiazole hybrids inspired from dehydrozingerone (DZG) scaffold were designed and synthesized by molecular hybridization approach. In vitro antimycobacterial activity of synthesized compounds was evaluated against Mycobacterium tuberculosis $\mathrm{H}_{37} \mathrm{Rv}$ strain. Among the series, compound $\mathbf{6 0}$ exhibited significant activity $\left(\mathrm{MIC}=1.5 \mu \mathrm{M} ; \mathrm{IC}_{50}=0.48 \mu \mathrm{M}\right)$ along with bactericidal $(\mathrm{MBC}=12 \mu \mathrm{M})$ and intracellular antimycobacterial activities $\left(\mathrm{IC}_{50}=<0.098 \mu \mathrm{M}\right)$. Furthermore, 6o displayed prominent antimycobacterial activity under hypoxic $(\mathrm{MIC}=46 \mu \mathrm{M})$ and normal oxygen $(\mathrm{MIC}=0.28 \mu \mathrm{M})$ conditions along with antimycobacterial efficiency against isoniazid ( $\mathrm{MIC}=3.2 \mu \mathrm{M}$ for INH-R1; $1.5 \mu \mathrm{M}$ for INH-R2) and rifampicin (MIC $=2.2 \mu \mathrm{M}$ for RIF-R1; $6.3 \mu \mathrm{M}$ for RIF-R2) resistant strains of Mtb. Presence of electron donating groups on the phenyl ring of thiazole moiety had positive correlation for biological activity, suggesting the importance of molecular hybridization approach for the development of newer DZG clubbed hydrazine thiazole hybrids as potential antimycobacterial agents.

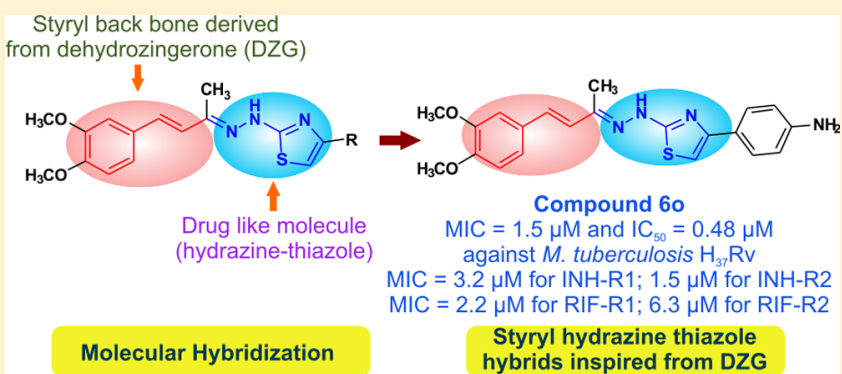

KEYWORDS: Antimycobacterial activity, bactericidal, dehydrozingerone, NIAID, thiazole

$\mathrm{T}$ uberculosis (TB) is a chronic necrotizing bacterial infection caused by Mycobacterium tuberculosis ( $\mathrm{Mtb}$ ), which has been a bane of humanity for thousands of years and remains as one of the rampant health problems in the world. $\mathrm{TB}$ is an ancient enemy, and current threat that has been ranked among the foremost killers of the 21st century. ${ }^{1}$ According to a World Health Organization (WHO) report, around 9 million people were found infected and around 1.5 million casualties occurred because of TB. Besides, the life threatening strains of MDR-TB (Multi Drug Resistance Tuberculosis) are appearing, some of which can lead to high mortality rate (e.g., 72-89\%) with death occurring in short period (4-16 weeks). ${ }^{2}$ In 2013 around 480,000 affirmative cases of MDR-TB were witnessed. ${ }^{3}$ India, China, the Russian Federation, and South Africa have almost $60 \%$ of the world's cases of MDR-TB. In addition, the risk becomes even greater if the person is coinfected with the HIV (human immunodeficiency virus). ${ }^{4}$ The global resurgence of TB and development of drug resistance necessitates for an imperative attention of medicinal chemists to develop innovative antimycobacterial agents as no new classes of anti-TB agents have been developed since the introduction of rifampin in to clinical practice in 1960s.

It is well-known fact that trans-cinnamic acid analogues have recently drawn back the intentness of medicinal chemists due to their admirable pharmacological properties like antioxidant, ${ }^{5}$ antibacterial, ${ }^{6}$ and antitumor. ${ }^{7}$ Rastogi et al. have demonstrated the synergistic activity of trans-cinnamic acid in amalgamation with INH, rifamycin, and other recognized antimicrobial agents against Mtb. ${ }^{8}$ Further, Reddy et al. have reported the superior intracellular and in vivo activity of a cinnamoyl-rifamycin derivative (Figure 1) in contrast with rifamycin when tested against susceptible and MDR strains of Mtb along with $M$. avium complex (MAC). ${ }^{9}$ Several compounds resembling cinnamic acid and bearing styryl group or $\alpha, \beta$-unsaturated

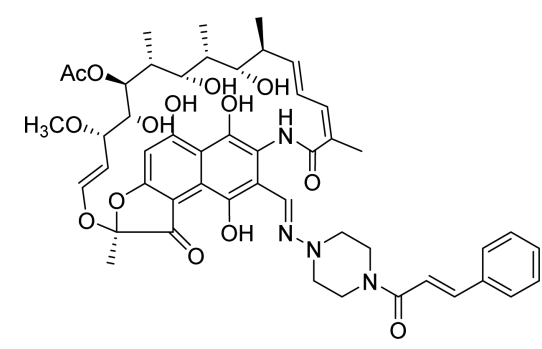

Figure 1. Cinnamoyl-rifamycin derivative.

Received: February 27, 2016

Accepted: May 13, 2016

Published: May 13, 2016 
carbonyl groups are reported for antimycobacterial activities (Figure 2). ${ }^{10}$

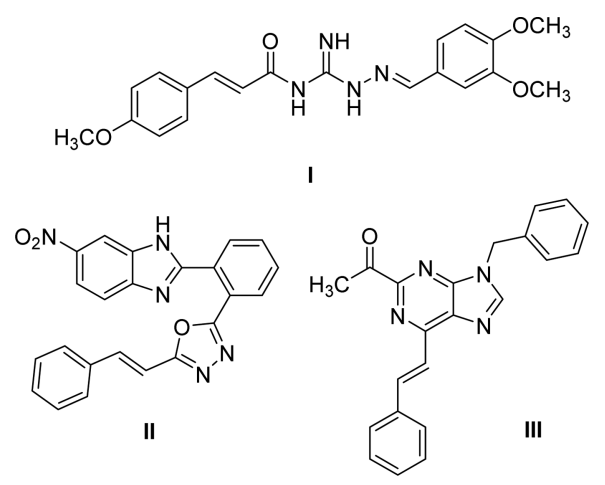

Figure 2. Compounds with styryl portion reported against $M$. tuberculosis $\mathrm{H}_{37} \mathrm{RV}$ : (I, MIC $6.49 \mu \mathrm{M}$ ); ${ }^{11}$ (II, MIC $12.5 \mu \mathrm{g} / \mathrm{mL}$ ); ${ }^{12}$ (III, MIC $6.25 \mu \mathrm{M})$. $^{13}$

From the literature, it was also found that derivatives resulting by combining cinnamoyl portion with various chemical classes of compounds have been reported to possess promising antimycobacterial activity. ${ }^{14-16}$ Besides, various drug-like heterocycles, namely, benzimidazoles ${ }^{17}$ and quinazolinones, ${ }^{18}$ integrated with cinnamoyl or aryl styryl groups have also been reported to augment the antimycobacterial properties.

Dehydrozingerone (DZG), also known as feruloylmethane, a half structural analogue of curcumin, is isolated from Curcuma longa. Chemically DZG is (E)-4-(4-hydroxy-3-methoxy phenyl)but-3-en-2-one and possess an $\alpha, \beta$-unsaturated carbonyl (styryl ketone) group that resembles the trans-cinnamic acid structure. DZG analogues have been reported to possess a broad range of biological activities like antioxidant, anticancer, anti-inflammatory, antidepressant, antimalarial, antifungal, etc. ${ }^{19}$

The thiazole nucleus is a common motif presently found in several FDA-approved drugs, such as the nonsteroidal antiinflammatory drug meloxicam ${ }^{20}$ and the tyrosine kinase inhibitor dasatinib. ${ }^{21}$ Recently, Meissner et al. have demonstrated the structure-activity relationships (SAR) of novel series of 2-aminothiazole analogues as effective antimycobacterial agents, ${ }^{22}$ and Carradori et al. have reported microwaveassisted method for the synthesis of substituted-thiazolyl hydrazines. ${ }^{23}$ Therefore, thiazole is an essential scaffold in drug discovery since its derivatives known to possess wide spectrum of activities such as antihypertensive, anti-inflammatory, anti-HIV, antibacterial, and antimycobacterial, ${ }^{24,25}$ which have tremendously captivated attention of medicinal chemists. Figure 3 highlights the molecular manipulation of DZGthiazole moiety and their resultant antimycobacterial activities.

In view of the above facts and in continuation of our research program on the design and development of new antimycobacterial agents ${ }^{19,24,29}$ it was foreseen to amalgamate two biologically active pharmacophores (styryl portion of DZG and thiazole) in one molecular platform to engender a new scaffold for antimycobacterial evaluation. As shown in Figure 3, the designed hybrid analogues possess both DZG (comprising styryl) and thiazole motifs connected with each other via a hydrazine linker. These unifications were suggested as an effort to explore the possible synergistic influence of such structural hybridizations on the anticipated activity, hoping to discover a

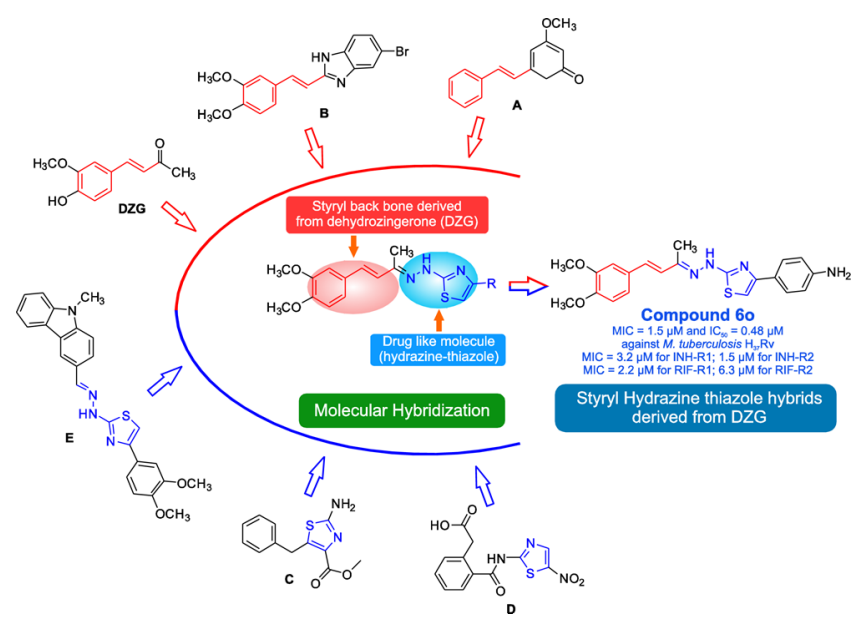

Figure 3. Literature reported derivatives containing styryl and thiazole moieties and their antimycobacterial activities along with the designed compounds. Compound 60 exhibited most promising antimycobacterial activity among the synthesized compounds. (A) (E)-3-methoxy-5styrylcyclohexa-2,4-dien-1-one (MIC against $\mathrm{H}_{37} \mathrm{Rv}=32 \mu \mathrm{g} / \mathrm{mL}$ ); ${ }^{26}$ (B) (E)-5-bromo-2-(3,4-dimethoxystyryl)-1H-benzo[d] imidazole (MIC against $\mathrm{H}_{37} \mathrm{Rv}=>7.25 \mu \mathrm{g} / \mathrm{mL}$ ); ${ }^{17}$ (C) 2-amino-5-benzylthiazole-4-carboxylate (MIC against $\mathrm{H}_{37} \mathrm{Rv}=0.06 \mu \mathrm{g} / \mathrm{mL}$ ); ${ }^{27}$ (D) nitazoxanide (MIC against $\mathrm{H}_{37} \mathrm{Rv}=16 \mu \mathrm{g} / \mathrm{mL}$ ); ${ }^{28}$ (E) carbazolothiazole analogue (MIC against $\mathrm{H}_{37} \mathrm{Rv}=21 \mu \mathrm{M}$ ). ${ }^{24}$

new lead structure that would have a promising antimycobacterial activity.

The synthesis of a novel series of styryl hydrazine thiazole hybrids derived from DZG $(6 \mathbf{6}-60)$ was achieved through efficient and versatile synthetic routes. The starting material DZG (2) was prepared by using commercially available vanillin (1) by simple aldol condensation with acetone in the presence of base. Methylation of $\mathbf{2}$ was done with methyl iodide in the presence of potassium carbonate in $N, N$-dimethylformamide to yield (E)-4-(3,4-dimethoxyphenyl)but-3-en-2-one (3). Further, Schiff base of compound 3 was formed with thiosemicarbazide to yield 4 (Scheme 1). The various appropriately substituted 2-

\section{Scheme $1^{a}$}
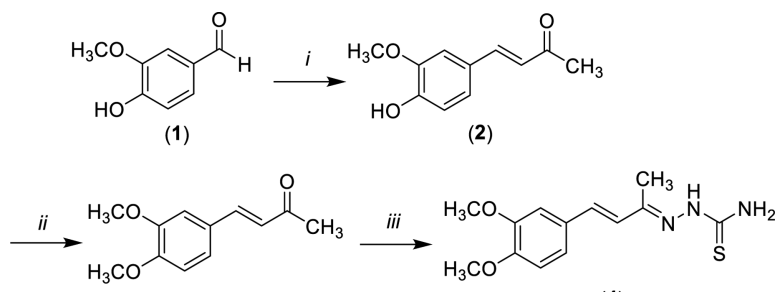

(3)

${ }^{a}$ Reaction conditions: (i) acetone, $\mathrm{NaOH}$; (ii) $\mathrm{CH}_{3} \mathrm{I}, \mathrm{K}_{2} \mathrm{CO}_{3}$, DMF, reflux, $1.5 \mathrm{~h}$; (iii) thiosemicarbazide, $\mathrm{AcOH}, \mathrm{CH}_{3} \mathrm{OH}$, reflux, $3 \mathrm{~h}$.

bromo-1-phenylethanones $(\mathbf{5 c - 5 o})$ were synthesized from their respective acetophenones. Compound (4) was then condensed with various freshly synthesized 2-bromo-1-(substituted phenyl)-ethanones $(\mathbf{5 a}-\mathbf{5 o})$ to yield corresponding final compounds, i.e., 2-(2-((2E,3E)-4-(3,4-dimethoxyphenyl)but-3-en-2-ylidene)hydrazinyl)-4-(substituted phenyl)thiazoles $(6 \mathbf{a}-60 ;$ Scheme 2). The anticipated structures of the final compounds were in agreement with the spectral (IR, ${ }^{1} \mathrm{H}$ NMR, and ${ }^{13} \mathrm{C}$ NMR) data obtained and were further substantiated by 
Scheme $2^{a}$

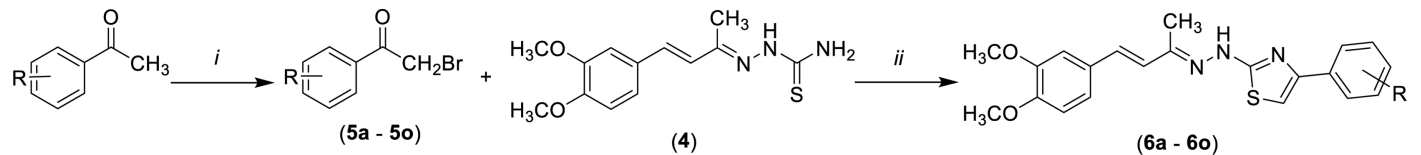

${ }^{a}$ Reaction conditions: (i) $\mathrm{Br}_{2}$, ether, $0-5{ }^{\circ} \mathrm{C}$ for $\mathbf{5 c} ; \mathrm{Br}_{2}, \mathrm{CHCl}_{3}$, reflux, $3 \mathrm{~h}$ for $\mathbf{5 d}$ and $\mathbf{5} \mathbf{g} ; \mathrm{Br}_{2}, \mathrm{CHCl}_{3}, 0-5{ }^{\circ} \mathrm{C}$ for $\mathbf{5 e}$ and $\mathbf{5 f}$; $\mathrm{CuBr}_{2}, \mathrm{EtOAc} \mathrm{CHCl}$, reflux, $12 \mathrm{~h}$ for $\mathbf{5 h - 5 0}$; (ii) methanol, reflux, $3 \mathrm{~h}$.

Table 1. Antimycobacterial Activity Data of Newly Synthesized Compounds (4, 6d, 6g, 6i, and 6o) against Five Drug-Resistant Isolates of M. tuberculosis $\mathrm{H}_{37} \mathrm{Rv}$

\begin{tabular}{|c|c|c|c|c|c|c|c|c|c|c|c|c|c|c|c|}
\hline \multirow[b]{2}{*}{ compd } & \multicolumn{3}{|c|}{ INH-R1 ${ }^{a}$} & \multicolumn{3}{|c|}{ INH-R $2^{b}$} & \multicolumn{3}{|c|}{ RIF-R1 ${ }^{c}$} & \multicolumn{3}{|c|}{ RIF-R2 ${ }^{d}$} & \multicolumn{3}{|c|}{$\mathrm{FQ}-\mathrm{R} 1^{e}$} \\
\hline & $\begin{array}{l}\mathrm{MIC} \\
(\mu \mathrm{M})\end{array}$ & $\begin{array}{c}\mathrm{IC}_{50} \\
(\mu \mathrm{M})\end{array}$ & $\begin{array}{l}\mathrm{IC}_{90} \\
(\mu \mathrm{M})\end{array}$ & $\begin{array}{c}\mathrm{MIC} \\
(\mu \mathrm{M})\end{array}$ & $\begin{array}{c}\mathrm{IC}_{50} \\
(\mu \mathrm{M})\end{array}$ & $\begin{array}{c}\mathrm{IC}_{90} \\
(\mu \mathrm{M})\end{array}$ & $\begin{array}{l}\mathrm{MIC} \\
(\mu \mathrm{M})\end{array}$ & $\begin{array}{l}\mathrm{IC}_{50} \\
(\mu \mathrm{M})\end{array}$ & $\begin{array}{c}\mathrm{IC}_{90} \\
(\mu \mathrm{M})\end{array}$ & $\begin{array}{l}\mathrm{MIC} \\
(\mu \mathrm{M})\end{array}$ & $\begin{array}{l}\mathrm{IC}_{50} \\
(\mu \mathrm{M})\end{array}$ & $\begin{array}{c}\mathrm{IC}_{90} \\
(\mu \mathrm{M})\end{array}$ & $\begin{array}{l}\text { MIC } \\
(\mu \mathrm{M})\end{array}$ & $\begin{array}{l}\mathrm{IC}_{50} \\
(\mu \mathrm{M})\end{array}$ & $\begin{array}{l}\mathrm{IC}_{90} \\
(\mu \mathrm{M})\end{array}$ \\
\hline 4 & 5.3 & 1.3 & 6.6 & 2.5 & 0.79 & 2.9 & 4 & 1.1 & 4.6 & 4.8 & 1.2 & 5.9 & 17 & 2.8 & 16 \\
\hline $6 d$ & 15 & 12 & $>50$ & 12 & 8 & $>50$ & 25 & 11 & $>50$ & 31 & 8.7 & $>50$ & 22 & 23 & $>50$ \\
\hline $6 g$ & 24 & 12 & $>200$ & 13 & 7.1 & 12 & 28 & 9.2 & 27 & 46 & 19 & $>200$ & 30 & 18 & $>200$ \\
\hline $6 i$ & 32 & 9.1 & $>25$ & 19 & 5.6 & $>25$ & 17 & 7 & 19 & 41 & 10 & $>25$ & 33 & 13 & $>25$ \\
\hline 60 & 3.2 & 0.68 & 3.8 & 1.5 & 0.38 & 1.7 & 2.2 & 0.54 & 2.6 & 6.3 & 0.76 & 9.2 & 21 & 2.3 & 33 \\
\hline rifampicin & 0.018 & 0.0084 & 0.022 & 0.0065 & 0.0047 & 0.012 & 2 & 1.2 & 2.3 & $>50$ & $>50$ & $>50$ & 0.027 & 0.013 & 0.039 \\
\hline isoniazid & $>200$ & $>200$ & $>200$ & $>200$ & $>200$ & $>200$ & 0.17 & 0.15 & 0.21 & 0.62 & 0.54 & 0.6 & 0.35 & 0.36 & 0.47 \\
\hline levofloxacin & 1.2 & 0.64 & 1.4 & 1.4 & 0.84 & 1.4 & 0.76 & 0.59 & 0.91 & 1.1 & 0.6 & 1.2 & 20 & 12 & 22 \\
\hline
\end{tabular}

${ }^{a} \mathrm{INH}-\mathrm{R} 1$ was derived from $\mathrm{H}_{37} \mathrm{Rv}$ and is a $k a t G$ mutant $\left(\mathrm{Y} 155^{*}=\right.$ truncation). ${ }^{b} \mathrm{INH}-\mathrm{R} 2$ is strain ATCC35822. ${ }^{c} \mathrm{RIF}-\mathrm{R} 1$ was derived from $\mathrm{H}_{37} \mathrm{Rv}$ and is a $\mathrm{n} r p o B$ mutant (S522L). ${ }^{d} \mathrm{RIF}-\mathrm{R} 2$ is strain ATCC35828. ${ }^{e} \mathrm{FQ}-\mathrm{R} 1$ is a fluoroquinolone-resistant strain derived from $\mathrm{H}_{37} \mathrm{Rv}$ and is a gyrB mutant (D94N). INH, isoniazid; RIF, rifampicin; FQ, Fluoroquinolone.

HRMS data, which is summarized in the Supporting Information.

The ${ }^{1} \mathrm{H}$ NMR spectrum of compound 4 exhibited the presence of distinctive singlet signals at around $\delta 10.22,8.22-$ $7.76,7.154-7.150,3.79-3.76$, and 2.11 for the $\mathrm{N}-\mathrm{H}$ proton, $\mathrm{NH}_{2}$ proton, second proton of phenyl ring, methoxyl $\left(\mathrm{OCH}_{3}\right)$ protons, and methyl $\left(\mathrm{CH}_{3}\right)$ protons indicating its formation by a process of simple carbon-nitrogen bond creation with thiosemicarbazide in the presence of acetic acid as catalyst. In addition, the appearance of most informative doublet signals around $\delta 6.81-6.77 \mathrm{ppm}(J=16.53 \mathrm{~Hz})$ and 7.06-7.01 $(J=$ $16.84 \mathrm{~Hz})$ confirms the presence of olefinic protons.

The ${ }^{1} \mathrm{H}$ NMR spectrum (400 and $600 \mathrm{MHz}, \mathrm{DMSO}-d_{6}$ ) of the final compounds $(\mathbf{6 a}-\mathbf{6 o})$ displayed some distinctive singlet signals at around $\delta 11.42-10.22 \mathrm{ppm}$ for $\mathrm{N}-\mathrm{H}$ proton, $\delta$ 7.21-7.20 for second and $\delta 7.12-7.08$ for sixth aromatic protons of DZG scaffold, and $\delta 2.17-2.08 \mathrm{ppm}$ for methyl $\left(\mathrm{N}=\mathrm{C}-\mathrm{CH}_{3}\right)$ protons, respectively. In addition, the most informative singlet signal resonated around $\delta 7.70-7.31 \mathrm{ppm}$, which was attributed to the aromatic proton at $\mathrm{H}-5$ of thiazole ring, thus indicating its formation through cyclo-condensation process. Whereas most characteristic doublet signals around $\delta$ 6.83-6.64 ppm $(J=16.52-16.24 \mathrm{~Hz}, \mathrm{Ph}-\mathrm{HC}=\mathrm{CH}-)$ and $\delta$ 7.57-6.91 ppm $(J=16.52-14.76 \mathrm{~Hz}, \mathrm{Ph}-\underline{\mathrm{HC}}=\mathrm{CH}-)$ evidently indicated the presence of olefinic protons. This observation was found in consistence with previously reported similar type of compounds. ${ }^{30}$ Further, the unique singlet signals resonating around $\delta 3.82-3.77 \mathrm{ppm}$ indicated the presence of methoxyl protons $\left(\mathrm{OCH}_{3}\right)$ on the third and fourth position of the DZG scaffold, while the hydroxyl $(\mathrm{OH})$ protons on aromatic ring resonated as singlet signals around $\delta$ 11.24-10.86 $\mathrm{ppm}$. The various signals appearing as either doublets or multiplets around $\delta 8.29-6.77 \mathrm{ppm}$ accounted for aromatic protons. The E-configuration was ascertained for all final derivatives on the basis of $2 \mathrm{D}$ NMR studies. These findings were further corroborated from their respective ${ }^{13} \mathrm{C}$ NMR spectra of the title compounds. The characteristic signals resonating at around $\delta$ 169.53-156.50 and 108.52-102.10 ppm were assigned to carbons C-2 and C-5 of thiazole ring. The most prominent carbon signals observed around $\delta$ 149.27-148.91 and 132.56-126.23 ppm accounted for aromatic carbons having methoxyl groups and olefinic ( $\mathrm{Ph}-$ $\mathrm{H} \underline{\mathrm{C}}=\underline{\mathrm{C}} \mathrm{H}-$ ) carbons, respectively. Further, the characteristic carbon signals appearing around $\delta$ 55.49-55.47 and 12.35$12.15 \mathrm{ppm}$ indicated the presence of methoxyl and methyl groups in the title compounds, while the various aromatic carbons resonated around $\delta 140.78-108.03$ ppm. Further, the fluorine containing compounds $6 \mathbf{k}$ and $6 \mathrm{~m}$ have been discussed, which results in a very characteristic NMR spectra and the $J_{\mathrm{CF}}$ values are represented in Tables $\mathrm{S} 1$ and $\mathrm{S} 2$ (Supporting Information).

Both level I and II (in vitro) characterizations of antimycobacterial activity of newly synthesized title compounds (4, 6a-6o) were carried out at Infectious Disease Research Institute (IDRI) within the National Institute of Allergy and Infectious Diseases (NIAID) screening program, Bethesda, $\mathrm{MD}$, USA. In the initial studies (level I), minimum inhibitory concentration (MIC) was established against $\mathrm{Mtb}$ strain $\mathrm{H}_{37} \mathrm{Rv}$ grown under aerobic conditions by using a dual read-out $\left(\mathrm{OD}_{590}\right.$ and fluorescence) assay procedure. All the synthesized compounds exhibited interesting and noteworthy activity profiles with MIC ranging from 1.5 to $>200 \mu \mathrm{M}$ against the tested mycobacterial strain (Table S3, Supporting Information).

Interestingly, it was observed that compound $4(\mathrm{MIC}=2.1$ $\mu \mathrm{M}$ ) having a thiourea group (without thiazole moiety) displayed encouraging antimycobacterial activity with an $\mathrm{IC}_{50}$ value of $0.98 \mu \mathrm{M}$. This evidently indicated that the DZG structural core has greatly contributed for antimycobacterial activity. This finding instigated us to explore brief SAR investigations in order to study the biological effects of various substituents on the aromatic ring at the fourth position of the thiazole moiety, which was in turn attached to DZG scaffold 
through a hydrazine linkage. Among tested series, compound 6o $(\mathrm{MIC}=1.5 \mu \mathrm{M})$ with $p$-amino $\left(\mathrm{NH}_{2}\right)$ group on phenyl ring at fourth position of thiazole moiety exhibited excellent antimycobacterial activity with $\mathrm{IC}_{50}$ value of $0.48 \mu \mathrm{M}$, whereas compounds 6d $(\mathrm{MIC}=15 \mu \mathrm{M}), 6 \mathrm{~g}(\mathrm{MIC}=16 \mu \mathrm{M})$, and $6 \mathbf{i}$ $(\mathrm{MIC}=28 \mu \mathrm{M})$ substituted with one or two methoxyl $\left(\mathrm{OCH}_{3}\right)$ groups on thiazolylphenyl ring exhibited good inhibitory activity with $\mathrm{IC}_{50}$ value of $8.4,7.4$, and $6.6 \mu \mathrm{M}$, respectively. In the case of compounds $6 \mathbf{j}(\mathrm{MIC}=40 \mu \mathrm{M})$ and 61 ( $\mathrm{MIC}=$ $88 \mu \mathrm{M})$ with a hydroxyl $(\mathrm{OH})$ group on the phenyl ring displayed considerable antimycobacterial activity with $\mathrm{IC}_{50}$ value of 24 and $23 \mu \mathrm{M}$, respectively. These findings demonstrate that the thiazole core contributed to enhanced activity and played a significant role in the action against Mtb. The activity was also considerably affected by the nature of the substituent on the phenyl ring at the fourth position of the thiazole nucleus. Consistent with our prior report, ${ }^{24}$ we found that the presence of electron donating $\left(\mathrm{NH}_{2}, \mathrm{OCH}_{3}\right.$, and $\left.\mathrm{OH}\right)$ groups on phenyl ring have greatly influenced and conferred good antimycobacterial activity, while the electron withdrawing $\left(\mathrm{CF}_{3}, \mathrm{NO}_{2}, \mathrm{~F}\right.$ and $\left.\mathrm{Br}\right)$ substituents have caused a decrease in activity. Thus, compounds $6 \mathrm{a}, \mathbf{6 c}, \mathbf{6 h}$, and $6 \mathrm{~m}$, having either nitro or halogen groups on the phenyl ring, were found to exhibit poor activity with MIC value $>200 \mu \mathrm{M}$. (Figure S1, Supporting Information). Compounds with promising antimycobacterial activity profile were further subjected for level II screening in order to evaluate their broad spectrum efficiency under assorted conditions against relevant drug resistant isolates of $\mathrm{Mtb}$ and other disease causing mycobacterial species.

The MIC of test compounds $(4,6 \mathbf{d}, \mathbf{6 g}, \mathbf{6 i}$, and $\mathbf{6 o}$ ) was assessed against five drug resistant isolates (INH-R1, INH-R2, RIF-R1, RIF-R2, and FQ-R1) of Mtb strains under aerobic conditions. The antimycobacterial activity results are summarized in Table 1. From perusal of the data, we observed that all tested compounds showed excellent antimycobacterial activity against INH-R1 and INH-R2, while two compounds (4 and 6o) exhibited the most promising antimycobacterial activity against the tested organisms. In particular, both resistant strains (R1 and R2) of INH and RIF were found to be extremely susceptible to compounds $\mathbf{4}$ and $\mathbf{6 0}$, while these two compounds had an almost comparable activity with that of Levofloxacin against FQ-R1. As compared to reference drug INH $\left(\mathrm{MIC}=>200 \mu \mathrm{M} ; \mathrm{IC}_{50}=>200 \mu \mathrm{M}\right)$, compounds $4(\mathrm{MIC}$ $=5.3$ and $2.5 \mu \mathrm{M} ; \mathrm{IC}_{50}=1.3$ and $\left.0.79 \mu \mathrm{M}\right)$ and $60(\mathrm{MIC}=3.2$ and $1.5 \mu \mathrm{M} ; \mathrm{IC}_{50}=0.68$ and $0.38 \mu \mathrm{M}$ ) displayed highest antimycobacterial activity against INH-R1 and INH-R2, respectively. In the case of RIF-R1 and RIF-R2, compound 6o $\left(\mathrm{MIC}=2.2\right.$ and $6.3 \mu \mathrm{M} ; \mathrm{IC}_{50}=0.54$ and $\left.0.76 \mu \mathrm{M}\right)$ exhibited significant antibacterial activity, whereas compounds $4\left(\mathrm{MIC}=4\right.$ and $4.8 \mu \mathrm{M} ; \mathrm{IC}_{50}=1.1$ and $\left.1.2 \mu \mathrm{M}\right)$ showed moderate activity when compared to reference drug RIF (MIC $=2$ and $\left.>50 \mu \mathrm{M} ; \quad \mathrm{IC}_{50}=>50 \mu \mathrm{M}\right)$. Nevertheless, the fluoroquinolone-resistant strain (FQ-R1) was found to be less susceptible to these compounds.

In addition, these five promising compounds (4, 6d, 6g, 6i, and 6o) were systematically assessed against $\mathrm{Mtb} \mathrm{H}_{37} \mathrm{Rv}$ grown under varied conditions. The antimicrobial activity of these compounds under hypoxic conditions was assessed using the low oxygen recovery assay (LORA). Further, the bactericidal (MBC: Minimum Bactericidal Concentration) activity of these compounds was assessed against $\mathrm{Mtb} \mathrm{H}_{37} \mathrm{Rv}$ grown in aerobic conditions in 7H9-Tw-OADC medium. The cytotoxicity and intracellular antimycobacterial activity of compounds was also determined using the THP-1 human monoocytic cell line, and THP1 cells infected with Mtb, respectively. The results of all these investigations are represented in Table S4 (Supporting Information). A systematic analysis of the data revealed that compounds 4 and 60 exhibited an interesting and potent antimycobacterial activity profile as depicted in Figure 4. All the

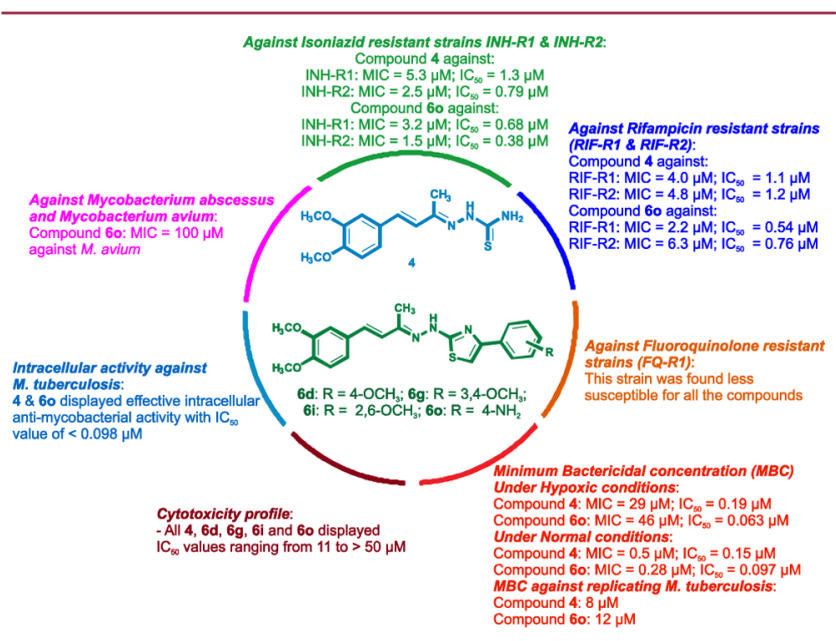

Figure 4. Anti-TB activity profile of most active compounds: $6 \mathrm{~d}, \mathrm{R}=$ $4-\mathrm{OCH}_{3} ; 6 \mathrm{~g}, \mathrm{R}=3,4-\mathrm{OCH}_{3} ; 6 \mathrm{i}, \mathrm{R}=2,6-\mathrm{OCH}_{3} ; \mathbf{6 o}, \mathrm{R}=4-\mathrm{NH}_{2}$.

five title compounds displayed an interesting cytotoxicity profile with $\mathrm{IC}_{50}$ values ranging from 11 to $>50 \mu \mathrm{M}$. Among the series tested, compounds $60\left(\mathrm{IC}_{50}=11 \mu \mathrm{M}\right)$ and $6 \mathbf{g}\left(\mathrm{IC}_{50}=38 \mu \mathrm{M}\right)$ showed moderate cytotoxicity, while other compounds did not show cytotoxic effect up to concentrations $>50 \mu \mathrm{M}$. The existence of virulent intracellular $\mathrm{Mtb}$ in primary human macrophages compromise its functioning and arrest phagosome maturation, thus coping up with various host threats. The aptitude of the bacteria to assault and survive inside cells may be implicated for the persistence of TB. Therefore, it is of greater corollary for an effective tuberculosis management that these compounds should also be capable of killing intracellular $\mathrm{TB}$ in human macrophages, apart from their in vitro activity against TB strains. Accordingly, two compounds (4 and 6o) also displayed effective intracellular antimycobacterial activity with $\mathrm{IC}_{50}$ value of $<0.098 \mu \mathrm{M}$. However, oxygen restriction also affects adaptive immune responses and triggers antimicrobial effector mechanisms in macrophages and restricts growth of intracellular $\mathrm{Mtb}$.

The title compounds $(4,6 \mathrm{~d}, 6 \mathrm{~g}, 6 \mathbf{i}$, and $6 \mathbf{6})$ were also evaluated for their in vitro antimycobacterial activity against other disease-relevant Mycobacterial species like Mycobacterium abscessus and Mycobacterium avium by using MABA method (Table S5, Supporting Information). The results reveal that compound 6o $(\mathrm{MIC}=100 \mu \mathrm{M})$ demonstrated a moderate activity especially against $M$. avium as compared to the reference drug RIF (MIC $=0.1 \mu \mathrm{M})$, while compound $6 \mathbf{i}$ displayed a MIC of $>100 \mu \mathrm{M}$ against $M$. abscessus and M. avium. However, the remaining compounds showed little or poor activity $(\mathrm{MIC}=>200 \mu \mathrm{M})$ against tested organisms.

In summary, in this work we established the synthesis of a series of styryl hydrazine thiazole hybrids derived from dehydrozingerone and their in vitro anti-TB activity. The ease, simply obtainable reactants and reagents, and practically good yields (51-74\%) make this synthetic method more attractive and efficient. Moreover, compound 6o emerged as most promising antimycobacterial agent since it has demon- 
strated most prominent activity under hypoxic condition along with its potential efficiency against drug resistant isolates of Mtb strains and displayed significant bactericidal and intracellular antimycobacterial activity. These findings suggest that the designed compounds highlighted the benefit of incorporating a hydrazine linkage to combine the styryl portion of DZG and the thiazole core, thus providing a good starting point for further lead optimization. The possible enhancement in the antimycobacterial activity can be further accomplished by slender variation in the ring substituents and/or extensive additional functionalization, which warrants further investigation.

\section{ASSOCIATED CONTENT}

\section{S Supporting Information}

The Supporting Information is available free of charge on the ACS Publications website at DOI: 10.1021/acsmedchemlett.6b00088.

Synthetic procedures, spectral data, and protocols of bioassay (PDF)

\section{AUTHOR INFORMATION}

\section{Corresponding Author}

*Phone: +27 31260 7179. Fax: +27 (0) 31260 7792. E-mail: karpoormath@ukzn.ac.za.

\section{Author Contributions}

The manuscript was written through contributions of all authors.

\section{Funding}

This work was supported by funds from the University of KwaZulu-Natal (UKZN), Westville Campus, Durban, South Africa.

Notes

The authors declare no competing financial interest.

\section{ACKNOWLEDGMENTS}

Authors sincerely thank National Institutes of Health and the National Institute of Allergy and Infectious Diseases (NIAID; Contract No.: HHSN272201100009I/HHSN27200002 A14), Bethesda, MD (USA), for in vitro antimycobacterial activity characterization. Authors are also grateful to Mr. Dilip Jagivan and Dr. Caryl Janse Van Rensburg (UKZN, South Africa) for their assistance in the NMR and HRMS experiments.

\section{REFERENCES}

(1) Herzog, H. History of Tuberculosis. Respiration 1998, 65 (1), 515.

(2) Collins, F. M. Mycobacterial Pathogenesis: A Historical Perspective. Front. Biosci., Landmark Ed. 1998, 3, e123-e132.

(3) World Health Organization. Global Tuberculosis Report 2014 (WHO/HTM/TB/2014.08); 2014.

(4) Bloom, B. R., Ed. Tuberculosis: Pathogenesis, Protection, and Control; ASM Press, 1994.

(5) Chung, H. S.; Shin, J. C. Characterization of Antioxidant Alkaloids and Phenolic Acids from Anthocyanin-Pigmented Rice (Oryza Sativa Cv. Heugjinjubyeo). Food Chem. 2007, 104 (4), 16701677.

(6) Guzman, J. Natural Cinnamic Acids, Synthetic Derivatives and Hybrids with Antimicrobial Activity. Molecules 2014, 19 (12), 1929219349.

(7) Bezerra, D. P.; Castro, F. O.; Alves, a. P. N. N.; Pessoa, C.; Moraes, M. O.; Silveira, E. R.; Lima, M. a S.; Elmiro, F. J. M.; CostaLotufo, L. V. In vivo Growth-Inhibition of Sarcoma 180 by Piplartine and Piperine, Two Alkaloid Amides from Piper. Braz. J. Med. Biol. Res. 2006, 39 (6), 801-807.

(8) Rastogi, N.; Goh, K. S.; Wright, E. L.; Barrow, W. W. Potential Drug Targets for Mycobacterium Avium Defined by Radiometric DrugInhibitor Combination Techniques. Antimicrob. Agents Chemother. 1994, 38 (10), 2287-2295.

(9) Reddy, V. M.; Nadadhur, G.; Daneluzzi, D.; Dimova, V.; Gangadharam, P. R. Antimycobacterial Activity of a New Rifamycin Derivative, 3-(4-Cinnamylpiperazinyl Iminomethyl) Rifamycin SV (T9). Antimicrob. Agents Chemother. 1995, 39 (10), 2320-2324.

(10) De, P.; Veau, D.; Bedos-Belval, F.; Chassaing, S.; Baltas, M. In Cinnamic Derivatives in Tuberculosis, Understanding Tuberculosis - New Approaches to Fighting Against Drug Resistance; Cardona, P.-J., Ed.; InTech, 2012.

(11) Bairwa, R.; Kakwani, M.; Tawari, N. R.; Lalchandani, J.; Ray, M. K.; Rajan, M. G. R.; Degani, M. S. Novel Molecular Hybrids of Cinnamic Acids and Guanylhydrazones as Potential Antitubercular Agents. Bioorg. Med. Chem. Lett. 2010, 20 (5), 1623-1625.

(12) Joshi, D. G.; Oza, H. B.; Parekh, H. H. Synthesis of Some Novel 1,3,4-Oxadlazoles and 5-Oxo-Imidazolines as Potent Biologically Active Agents. Heterocycl. Commun. 1997, 3 (2), 169-174.

(13) Bakkestuen, A. K.; Gundersen, L.-L.; Langli, G.; Liu, F.; Nolsøe, J. M. 9-Benzylpurines with Inhibitory Activity against Mycobacterium Tuberculosis. Bioorg. Med. Chem. Lett. 2000, 10 (11), 1207-1210.

(14) Carvalho, S. A.; da Silva, E. F.; de Souza, M. V. N.; Lourenço, M. C. S.; Vicente, F. R. Synthesis and Antimycobacterial Evaluation of New Trans-Cinnamic Acid Hydrazide Derivatives. Bioorg. Med. Chem. Lett. 2008, 18 (2), 538-541.

(15) De, P.; Koumba Yoya, G.; Constant, P.; Bedos-Belval, F.; Duran, H.; Saffon, N.; Daffé, M.; Baltas, M. Design, Synthesis, and Biological Evaluation of New Cinnamic Derivatives as Antituberculosis Agents. J. Med. Chem. 2011, 54 (5), 1449-1461.

(16) Rastogi, N.; Goh, K. S.; Horgen, L.; Barrow, W. W. Synergistic Activities of Antituberculous Drugs with Cerulenin and Trans -Cinnamic Acid against Mycobacterium Tuberculosis. FEMS Immunol. Med. Microbiol. 1998, 21 (2), 149-157.

(17) Shingalapur, R. V.; Hosamani, K. M.; Keri, R. S. Synthesis and Evaluation of in vitro Anti-Microbial and Anti-Tubercular Activity of 2Styryl Benzimidazoles. Eur. J. Med. Chem. 2009, 44 (10), 4244-4248.

(18) Babu, R. R.; Naresh, K.; Ravi, A.; Madhava Reddy, B.; Harinadha Babu, V. Synthesis of Novel Isoniazid Incorporated Styryl Quinazolinones as Anti-Tubercular Agents against INH Sensitive and MDR M. Tuberculosis Strains. Med. Chem. Res. 2014, 23 (10), 44144419.

(19) Hampannavar, G. A.; Karpoormath, R.; Palkar, M. B.; Shaikh, M. S. An Appraisal on Recent Medicinal Perspective of Curcumin Degradant: Dehydrozingerone (DZG). Bioorg. Med. Chem. 2016, 24 (4), 501-520.

(20) Luger, P.; Daneck, K.; Engel, W.; Trummlitz, G.; Wagner, K. Structure and Physicochemical Properties of Meloxicam, a New NSAID. Eur. J. Pharm. Sci. 1996, 4, 175-187.

(21) Das, J.; Chen, P.; Norris, D.; Padmanabha, R.; Lin, J.; Moquin, R. V.; Shen, Z.; Cook, L. S.; Doweyko, A. M.; Pitt, S.; Pang, S.; Shen, D. R.; Fang, Q.; De Fex, H. F.; McIntyre, K. W.; Shuster, D. J.; Gillooly, K. M.; Behnia, K.; Schieven, G. L.; Wityak, J.; Barrish, J. C. 2Aminothiazole as a Novel Kinase Inhibitor Template. StructureActivity Relationship Studies toward the Discovery of N-(2-Chloro-6Methylphenyl)-2-[[6- [4-(2-Hydroxyethyl)-1-Piperazinyl]-2-Methyl-4Pyrimidinyl]amino]-1, 3-Thiazole-5-Carboxamide (Dasatinib, BMS354825) as a Potent pan-Src Kinase Inhibitor. J. Med. Chem. 2006, 49 (23), 6819-6832.

(22) Meissner, A.; Boshoff, H. I.; Vasan, M.; Duckworth, B. P.; Barry, C. E.; Aldrich, C. C. Structure-Activity Relationships of 2-Aminothiazoles Effective against Mycobacterium Tuberculosis. Bioorg. Med. Chem. 2013, 21 (21), 6385-6397.

(23) Carradori, S.; Secci, D.; D’Ascenzio, M.; Chimenti, P.; Bolasco, A. Microwave and Ultrasound-Assisted Synthesis of Thiosemicarbazones and Their Corresponding (4,5-Substituted-Thiazol-2-Yl)hydrazines. J. Heterocycl. Chem. 2014, 51 (6), 1856-1861. 
(24) Shaikh, M. S.; Palkar, M. B.; Patel, H. M.; Rane, R. A.; Alwan, W. S.; Shaikh, M. M.; Shaikh, I. M.; Hampannavar, G. A.; Karpoormath, R. Design and Synthesis of Novel Carbazolo-thiazoles as Potential Anti-Mycobacterial Agents Using a Molecular Hybridization Approach. RSC Adv. 2014, 4 (107), 62308-62320.

(25) Villemagne, B.; Flipo, M.; Blondiaux, N.; Crauste, C.; Malaquin, S.; Leroux, F.; Piveteau, C.; Villeret, V.; Brodin, P.; Villoutreix, B. O.; Sperandio, O.; Soror, S. H.; Wohlkönig, A.; Wintjens, R.; Deprez, B.; Baulard, A. R.; Willand, N. Ligand Efficiency Driven Design of New Inhibitors of Mycobacterium Tuberculosis Transcriptional Repressor EthR Using Fragment Growing, Merging, and Linking Approaches. J. Med. Chem. 2014, 57 (11), 4876-4888.

(26) Mata, R.; Morales, I.; Pérez, O.; Rivero-Cruz, I.; Acevedo, L.; Enriquez-Mendoza, I.; Bye, R.; Franzblau, S.; Timmermann, B. Antimycobacterial Compounds from Piper S Anctum. J. Nat. Prod. 2004, 67 (12), 1961-1968.

(27) Al-Balas, Q.; Anthony, N. G.; Al-Jaidi, B.; Alnimr, A.; Abbott, G.; Brown, A. K.; Taylor, R. C.; Besra, G. S.; McHugh, T. D.; Gillespie, S. H.; Johnston, B. F.; Mackay, S. P.; Coxon, G. D. Identification of 2Aminothiazole-4-Carboxylate Derivatives Active against Mycobacterium Tuberculosis $\mathrm{H}_{37} \mathrm{Rv}$ and the $\beta$-Ketoacyl-ACP Synthase mtFabH. PLoS One 2009, 4 (5), e5617.

(28) de Carvalho, L. P. S.; Lin, G.; Jiang, X.; Nathan, C. Nitazoxanide Kills Replicating and Nonreplicating Mycobacterium Tuberculosis and Evades Resistance. J. Med. Chem. 2009, 52 (19), 5789-5792.

(29) Palkar, M. B.; Noolvi, M. N.; Maddi, V. S.; Ghatole, M.; Nargund, L. G. Synthesis, Spectral Studies and Biological Evaluation of a Novel Series of 2-Substituted-5,6-Diarylsubstituted imidazo(2,1-B)1,3,4-Thiadiazole Derivatives as Possible Anti-Tubercular Agents. Med. Chem. Res. 2012, 21 (7), 1313-1321.

(30) Kubra, I. R.; Bettadaiah, B. K.; Murthy, P. S.; Rao, L. J. M. Structure-Function Activity of Dehydrozingerone and Its Derivatives as Antioxidant and Antimicrobial Compounds. J. Food Sci. Technol. 2014, 51 (2), 245-255. 